\title{
Effect of Purple Passion Fruit Juice on Total Cholesterol of Atherogenic Wistar Rat
}

\author{
Farah Paramita ${ }^{1, *}$ Hiya Alfi Rahmah ${ }^{2}$ \\ ${ }^{1}$ Department of Public Health, Faculty of Sport Science, Universitas Negeri Malang, Malang, East Java, Indonesia \\ ${ }^{2}$ Nutrition Science Study Program, Faculty of Health Sciences, Jenderal Soedierman University Purwokerto, \\ Indonesia \\ *Corresponding author. Email : farah.paramita.fik@um.ac.id
}

\begin{abstract}
Dyslipidemia is one of the main factor causing atherosclerosis. Dyslipidemia is lipoprotein metabolism disorder which is marked by an increasing of total cholesterol in blood serum. One of the nutrient that can be used to reducing cholesterol synthesis in hepar and inhibit lipid peroxidation is betacaroten that found in purple passion fruit. It contain $1070 \mu \mathrm{g}$ betacaroten also the other antioksidan such as Vitamin A, Vitamin C, flavonoid and fiber. We conduct experimental study to find out the effect of purple passion fruit juice to total cholesterol in atherogenic wistar rat. We used 30 wistar male rat and randomly divided into 5 groups which received different treatment (normal diet; atherogenic diet; atherogenic diet $+2,3 \mathrm{ml} / \mathrm{kg}$ purple passion fruit juice; atherogenic diet $+3,3 \mathrm{ml} / \mathrm{kg}$ purple passion fruit juice; atherogenic diet $+4,2 \mathrm{ml} / \mathrm{kg}$ purple passion fruit juice with gavage treatment) for 60 days. ANOVA was perform to find out the cholesterol total different in each group. This study show that there was no significant different in total cholesterol wistar male rat $(\mathrm{p}=0.057)$, but compare to group which was not given purple passion fruit juice, it show that there was a trend in reducing total cholesterol as we increased amount purple passion fruit given to wistar male rat. It need further investigation about effective dosage of purple passion fruit juice to reducing total cholesterol serum of rats.
\end{abstract}

Keywords: purple passion fruit juice, total cholesterol, atherogenic diet, randomized control trial.

\section{INTRODUCTION}

Coronary heart disease is the leading cause of death in developed countries and is one of the leading causes of disease burden in developing country [1]. Around 17.8 million people died from cardiovascular disease in 2019, representing $32 \%$ of all global death, mostly because of heart attact and stroke [2]. According to the basic health research in Indonesia, prevalence of heart disease is about $1.5 \%$ based on doctor's diagnosis [3].

Coronary heart disease is caused by atherosclerosis, characterized by hardening and narrowing of the arteris. This is due to the presence of plaque on the walls of blood vessels. Plaque is formed fat, cholesterol, calcium and other substances present in the blood and it can blocked blood flow. Dislipidema is a major risk factor of atherosclerosis. Dislipidemia is a lipoprotein metabolism disorder characterized by an increasing in total cholesterol, LDL (Low Density Lipoprotein), TG (trigliseride) and decreased in HDL (High Density of Lipoprotein [4]. Previous study showed that an increasing of cholesterol level were associated with elevated Cardiovascular Disease risk [5].

According to clinical studies, a correct diet such as consuming diet rich in fruit and vegetables can prevent cardiovascular disease [6]. Increasing consumption of plant-based diet food has been linked with promoting health and well being by reducing cardiovascular disease risk, as they rich source of fiber and essential micronutrient such as vitamins, minerals, and bioactive compound including flavonoid, phenolic acid, carotenoids and plant sterol [7]. However, passion fruit appears to be excellent souce of nutrient. Passion fruit is a tropical fruit that has been known in Indonesia. It has a very distinctive aroma and can be freshly consume with seeds or processed into syrup. Several types of passion fruit that cultivated commercially included purple passion fruit. Purple passion fruit is the main ingredient of industrial passion fruit juice [8]. The fruit has a high content of phenolic acids and carotenoids (betacaroten appear to be the principal component) [9]. In $100 \mathrm{ml}$ of passion fruit juice contains $1070 \mu \mathrm{g}$ betacaroten [10] 
Previous study showed potential of passion fruit as a herbal medicine source as a antihypercholesterolemic agent. It showed that dry extract of passion fruit significantly reduced total cholesterol, triglyceride and LDL level and increased of HDL level [11]. Based on this, we find out the effectivity of purple passion fruit juice to total cholesterol in atherogenic wistar rat.

\section{METHOD}

\subsection{Subjects}

This experimental study used 30 white male Rattus Novergicus Wistar Rat, 2 months old, 150 - 200 gr weights. This rats were randomly divided into 5 groups and were given treatment for 60 days : K- was given normal diet without any other treatment; $\mathrm{K}+$ was given atherogenic diet and water as a placebo, P1 was given atherogenic diet with $2,3 \mathrm{ml} / \mathrm{kg}$ purple passion fruit juice; P2 was given atherogenic diet with $3,3 \mathrm{ml} / \mathrm{kg}$ purple passion fruit juice; P3 was given atherogenic diet with $4,3 / \mathrm{kg} \mathrm{ml}$ purple passion fruit juice. The juice and the placebo were administered by oral gavage.

\subsection{Purple Passion Fruit Juice Preparation}

The fruits were obtain from Lowokwaru Area, Malang city. It was washed and cut into two part. The edible part was blend using blender without water added for 1 minutes. The fruit juice was filtered using filter cloth. The fruite juice was made everyday before administrated into wistar rat.

\subsection{Atherogenic Diet Preparation}

A total of 40 grams of atherogenic diet was given to rats with various doses of purple passion fruit juice including group $\mathrm{K}+, \mathrm{P} 1, \mathrm{P} 2$ and $\mathrm{P} 3$. The atherogenic diet consist of comfeed PARS, wheat flour, duck egg yolk, goat fat, coconut oil, pork oil and cholic acid. The atherogenic diet ingredient was weighed then mixed it together. The mixture was added by water then forming into spheres. It was weighed and given orally to wistar rat.

\subsection{Variabel Measurement}

The dependent variable of this study was total cholesterol levels in the serum of male wistar rattus novergicus rats. Total cholesterol levels in the serum samples were measured after 60 days of treatment. The blood serum samples were examined using colorimetric spectropohotometry using the Cobas Mira instrument. Wistar rats are anesthetized with ether until they fainted, then fissected and blood taken form the heart of ventricle. The implementation of measurement is at wavelength of $510 \mathrm{~nm},(490-550$ intervals). Using a $1 \mathrm{~cm}$ cuvette at $37^{\circ} \mathrm{C}$. measurements were made by comparing blank reagents.

\subsection{Statistical Analysis}

Data analysis was carried out quantitatively. Data distribution was tested with shapiro wilk and Levene tested the homogeneity of the data. One Way Anova test was conducted to compare mean level of the parameters tested between groups. One Way Anova test was significant if it was obtained $\mathrm{p}<0.05$.

\section{RESULTS}

\subsection{Wistar Rat Body Weight}

Measurement of wistar rat was performed every weeks during research period ( 8 weeks). The average of wistar rat body weight during research period is presented in Figure 1 below. It showed that the all of wistar rat in each group has developing weight gain in each week. The heaviest wistar body weight were found in P2 group .

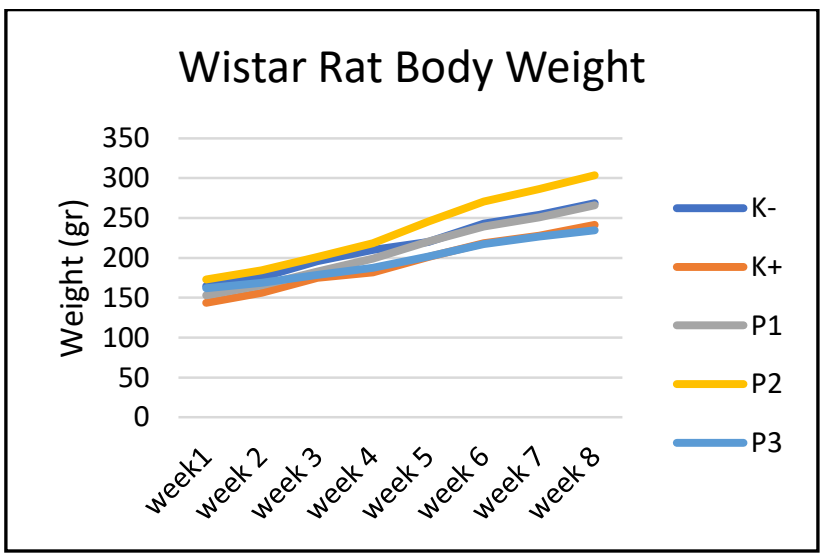

Figure 1. Wistar Rat Body Weight

\subsection{Wistar Rat Intake}

The wistar rat intake was shown in the figure 2. Feed intake of wistar rat was obtain through the difference between the weight of feed given and the weight of feed remain. One way anova test show that there was a significant different in feed intake between five groups $(p=0,007)$. The highest feed intake was found in $\mathrm{K}$ - that given normal diet and the lowest intake was found in P4 that receive atherogenic diet and purple passion juice 4,3 $\mathrm{ml}$.

Enegy intake was obtain from conversion feed intake into calories. One way anova test show that there was a significant different in energy intake between five groups. The highest energy intake was found in P2 that were receid atherogenic diet and the lowest energy intake was found in $\mathrm{K}$ - that received normal diet. 
Carbohydrate and fat intake among five groups also shows significant different $(\mathrm{p}=0.000)$. the highest carbohydrate intake was found in $\mathrm{K}$ - and the lowest was found in P3. The highest fat intake was found in P2 and the lowest was found on $\mathrm{K}$ - that received normal diet.

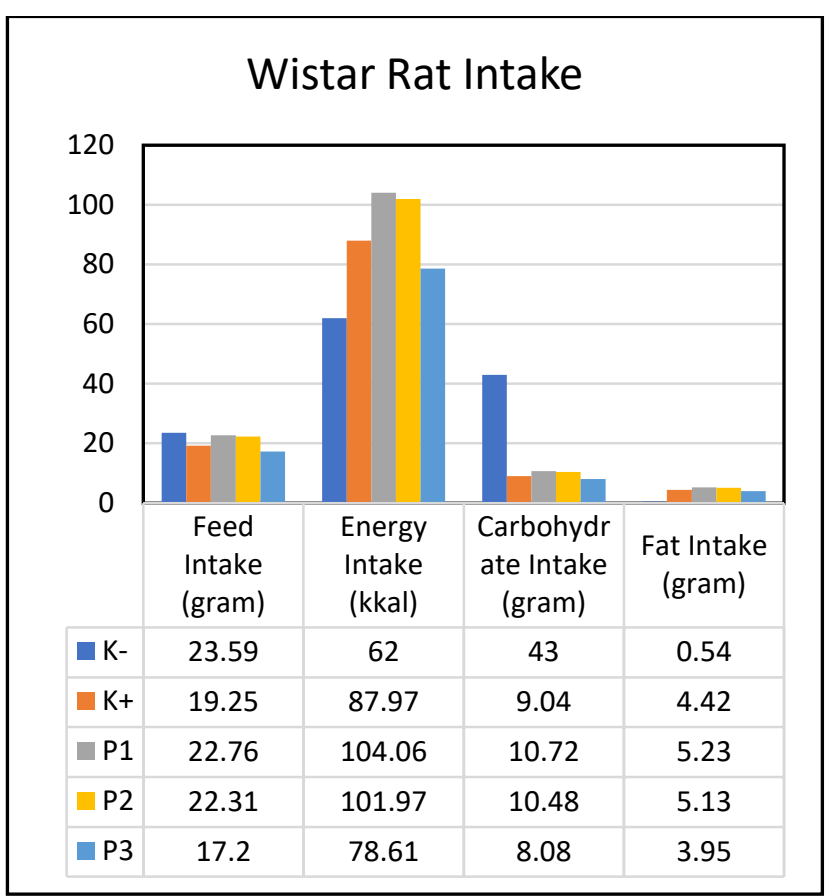

Figure 2. Wistar Rat Intake

\subsection{Total Cholesterol Level}

Measurement of total cholesterol level of rats was performed after all groups were received treatment for 60 days. It showed that total cholesterol levels of wistar rats were increased after being given by an atherogenic diet. The P1 group (passion fruit juice 2,3 ml) was the group with the highest total of cholesterol level $(66 \pm 9.3)$ while the $\mathrm{P} 3$ group (given passion fruit juice 2,3 ml) was the lowest level of cholesterol in treatment group that received atherogenic diet. One way anova test showed that there was no significant different between group $(p=0.057)$. Compare to group which was not given purple passion fruit juice, it show that there was a trend in reducing total cholesterol as we increased amount purple passion fruit given to wistar male rat that showed in figure 3 .

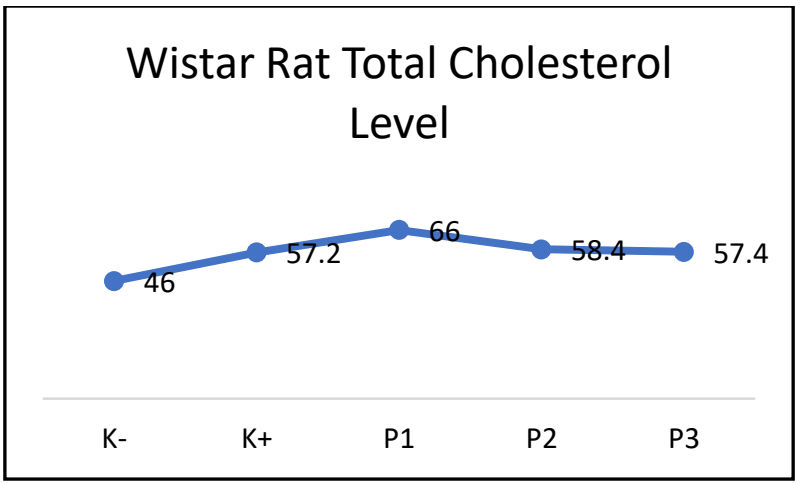

Figure 3. Wistar Rat Total Cholesterol Level

\section{DISCUSSION}

Atherosclerosis is defined as chronic inflammatory disease of the inner wall of large and medium size arteries [12]. It develops progressively with contious evolution of arterial wall lesions centered on the accumulation of cholesterol-rich lipid accompanied by inflammatory response [13]. In this study we perform experimental study in atherogenic animal model using wistar rat. An atherogenic diet consist of cholesterol, cholic acid and fat, in which the cholesterol and cholic acid component play an important and significant role in proatherogenic properties. The atherogenic diet used in this study can increase body and weight total cholesterol in wistar rat. The weight of animal is considered as an additional contributing factor in the increase in cholesterol level in blood [14].

Purple passion fruit contains antioxidant component including betacaroten, vitamin $\mathrm{C}$ and polyphenols. The ability of betacaroten as an antioxidant was shown to bind oxygen $\left(\mathrm{O}_{2}\right)$, scavaging peroxyl radicals and inhibiting lipid peroxidation. In addition betacaroten also has hypocholesterolemic activity because it can reduce cholesterol synthesis in liver through the inhibition mechanism of HMG CoA Reductase [15]. Vitamin C is also have a hypocholesterolemic function by converting cholesterol into bile acids which is the main pathway in cholesterol catabolism along with an increasing of bile acid through feces and liver by activating $7-\alpha$ hydroxylase [16].

This study showed that there is no significant different in cholesterol level of wistar rat between five groups but among the three group receiving purple passion fruit juice there was trend in reducing total cholesterol level as we increased the passion fruit juice. The previous research using passion fruit juice showed the significant result in reducing total cholesterol in diabetic rat. This study used passion fruit juice at dose of $0.58 \mathrm{~g} / \mathrm{kg}$ once a day for 30 consecutive days [11]. Another study used purple passion fruit juice to hypercholesterolemic wistar rat also showed the significant different. The provision of various dose of purple passion fruit juice can improves lipid profile, 
whare dose of $4.2 \mathrm{ml} / 200 \mathrm{gBB} /$ day can significantly lower total cholesterol level [17].

Our study showed the difference result from the previous study because it has the different design study. Our study used post test only control group design while the previous one used pre-post test control group design. The passion fruit juice used in our study not involving the pulp because we strain the fruit juice before administrated to wistar rat. The positif effect of passion fruit may related to the compound in its pulp. Passiflora species are rich in pectin, mineral, carotenoids, vitamin $\mathrm{C}$ and flavonoids. Study showed that pectin can reduce total cholesterol level. Fiber might reduce plasma lipid levels by increasing the escretion of cholesterol and biliary acids in feces [11].

\section{CONCLUSION}

The purple passion fruit juice in this study has not been able to cause a therapeutic effect in reducing total cholesterol although it has trend in lowering total cholesterol in treatment group. It is suggested to use the pulp of passion fruit and investigate the effective dosage to lowering lipid profile for future research.

\section{AUTHOR'S CONTRIBUTION}

All authors conceived, design the study and conducted experiment. FP analyzed and wrote the paper. All author read and approved the final manuscript.

\section{ACKNOWLEDGMENTS}

We would like to thank all of the passiflora team for the valuable contribution and support.

\section{REFERENCES}

[1] Gaziano TA, Bitton A, Anand S, Abrahams-Gessel S, Murphy A. Growing Epidemic of Coronary Heart Disease in Low- and Middle-Income Countries. Curr Probl Cardiol 2010;35:72-115. https://doi.org/10.1016/j.cpcardiol.2009.10.002.

[2] WHO. Cardiovascular Disease (CVD’s) 2021.

[3] Badan Penelitian dan Pengembangan Kesehatan Kemenkes RI. Laporan Nasional Riskesdas 2018 FINAL.pdf. Badan Penelit Dan Pengemb Kesehat 2018:198.

[4] Cipla Initiative. Dyslipidemia, 2005. https://doi.org/10.1016/b978-1-4831-68135.50001-4.

[5] Jeong SM, Choi S, Kim K, Kim SM, Lee G, Park $S Y$, et al. Effect of change in total cholesterol levels on cardiovascular disease among young adults. J Am Heart Assoc 2018;7. https://doi.org/10.1161/JAHA.118.008819.
[6] Sharifi-Rad J, Rodrigues CF, Sharopov F, Docea AO, Karaca AC, Sharifi-Rad M, et al. Diet, lifestyle and cardiovascular diseases: Linking pathophysiology to cardioprotective effects of natural bioactive compounds. vol. 17. 2020. https://doi.org/10.3390/ijerph17072326.

[7] Milenkovic D, Morand C, Cassidy A, Konic-Ristic A, Tomás-Barberán F, Ordovas JM, et al. Interindividual variability in biomarkers of cardiometabolic health after consumption of major plant-food bioactive compounds and the determinants involved. Adv Nutr 2017;8:558-70. https://doi.org/10.3945/an.116.013623.

[8] Rukmana R. Usaha Tani Markisa. Yogyakarta: Kanisius; 2003.

[9] Ramaiya SD, Bujang JB, Zakaria MH, Saupi N. Nutritional, mineral and organic acid composition of passion fruit (Passiflora species). Food Res 2019;3:231-40.

https://doi.org/10.26656/fr.2017.3(3).233.

[10] dos Reis LCR, Facco EMP, Salvador M, Flôres SH, de Oliveira Rios A. Antioxidant potential and physicochemical characterization of yellow, purple and orange passion fruit. J Food Sci Technol 2018;55:2679-91. https://doi.org/10.1007/s13197018-3190-2.

[11] Barbalho SM, Damasceno DC, Spada APMH, Lima IEDRN, Araújo AC, Guiguer EL, et al. Effects of passiflora edulis on the metabolic profile of diabetic wistar rat offspring. J Med Food 2011;14:1490-5. https://doi.org/10.1089/jmf.2010.0318.

[12] Alfarisi HAH, Mohamed ZBH, Ibrahim M Bin. Basic pathogenic mechanisms of atherosclerosis. Egypt J Basic Appl Sci 2020;7:116-25. https://doi.org/10.1080/2314808x.2020.1769913

[13] Insull W. The Pathology of Atherosclerosis: Plaque Development and Plaque Responses to Medical Treatment. Am J Med 2009;122:S3-14. https://doi.org/10.1016/j.amjmed.2008.10.013.

[14] Dzul Fithria Mumtazah, Hendri Busman, Gina Dania Pratami, Ahad Putra Dewantara, Faradhila Amanda. Modification of atherogenic diet causes atherosclerosis, increase total cholesterol, and showing hepar damage in mice as alternative animal model in atherosclerosis research. GSC Biol Pharm Sci 2021;14:001-6. https://doi.org/10.30574/gscbps.2021.14.2.0402.

[15] Mukherjee PK. Plant products with hypocholesterolemic potentials. Adv Food Nutr Res 2003;47:277-338. https://doi.org/10.1016/S10434526(03)47005-8.

[16] Salem SA, Hassan DR, Mowafy AR. a Comparative Impact of Diffeerent Types of Single Antioxidant Supplementation on Lipid Profile in Hyperlipidemic Rats. Middle-East J Sci Res 2009;4:354-60. 
[17] Muntafiah A, Ernawati DA, Suryandhana L, Pratiwi RD, Marie A. Pengaruh Sari Markisa Ungu [Passiflora edulis var edulis] Berbagai Dosis terhadap Profil Lipid Tikus Wistar Model Hiperkoletrolemia (The Effectof Various Doses of Purple Passion [Passiflora edulis var edulis] Juice on the Lipid Profile of HYpercholestrole. J Penelit Gizi Dan Makanan 2017;40:1-8. 